\title{
A importância dos sinais dermatológicos para o diagnóstico de Esclerose Tuberosa: Relato de caso
}

\section{The importance of the dermatological signs on the diagnosis of Tuberous Sclerosis: Case report.}

\author{
Paula de Oliveira Varella ${ }^{1}$ \\ Leandro Dinato Dutra ${ }^{1}$ \\ Suindara Reis Serrazina ${ }^{1}$ \\ Viviane Dias Balbino ${ }^{1}$ \\ Cláudia Yamada Utagawa ${ }^{2}$
}

\begin{abstract}
Palavras-chave:
Esclerose Tuberosa

\section{Resumo}

Angiofibromas

Esclerose Tuberosa (ET) ou Síndrome de Bourneville é uma doença genética de caráter autossômico dominante. Resulta de mutações nos genes supressores tumorais ET-1 e ET-2 e caracteriza-se pela formação de tumores benignos denominados hamartomas, localizados em múltiplos

Manchas

hipocrômicas órgãos, afetando principalmente a pele e o cérebro. Relata-se o caso de um adolescente, sexo masculino, 19 anos de idade que apresenta angiofibromas em região nasal, malar e mentoniana, fibromas subungueais, manchas hipocrômicas pelo corpo, além de acometimento neurológico com crises convulsivas. A ET foi diagnosticada quando o paciente tinha seis meses de idade, por uma dermatologista após um episódio de crise convulsiva concomitante ao aparecimento das manchas hipocrômicas. É de grande importância o alerta médico para a presença de manifestações típicas da ET, já que o diagnóstico precoce é determinante no que diz respeito à evolução e ao prognóstico. Finalmente, destaca-se a importância do aconselhamento genético.
\end{abstract}

\begin{abstract}
Tuberous Sclerosis (TS) or Bourneville Syndrome is a genetic autosomal dominant disease. It is a result of mutations on the TSC1 and TSC2 genes, and it is characterized by the benign tumors' formation named hamartomas, located in multiple organs, which affects, specially, the skin and the brain. This is a 19 years old male adolescent's report, with cutaneous features, angiofibroma on the nasal, malar and mentonian areas, ungual fibromas, hypochromic spots on the body, besides neurological features and epilepsy. In these current TS case, a dermatologist diagnosed it after a seizure concomitant to the appearance of the hypochromic spots when the patient was 6 months old. The doctors' attention to the TS typical sign presence is extremely important for earlier diagnosis and it is determinant regarding evolution and prognosis. Finally, the genetic counseling is underlined.
\end{abstract}

Key words:

Tuberous Sclerosis

Angiofibromas

Hypochromic spots 


\section{Introdução}

A Esclerose Tuberosa (ET) é uma doença genética rara, de caráter autossômico dominante, caracterizada pela tríade: epilepsia, retardo mental e formação de tumores benignos hamartomatosos, que podem ser localizados em qualquer órgão, sendo que, frequentemente, os mais atingidos são a pele e o cérebro ${ }^{1}$.

O nome da patologia em questão derivase da descrição de lesões tumorais feita por Bourneville em 1880, sendo, por isso, também conhecida como Síndrome de Bourneville ou ainda Epiloia (Epi: Epilepsia; loi: Baixa inteligência; a: Adenoma sebáceo). Acomete ambos os sexos e todas as raças na mesma proporção, numa incidência em torno de 1:10.000. Na maioria dos doentes, o diagnóstico é estabelecido entre os 2 e 6 anos de idade ${ }^{2}$.

A ET é classificada como uma síndrome neurocutânea com manifestações dermatoló-

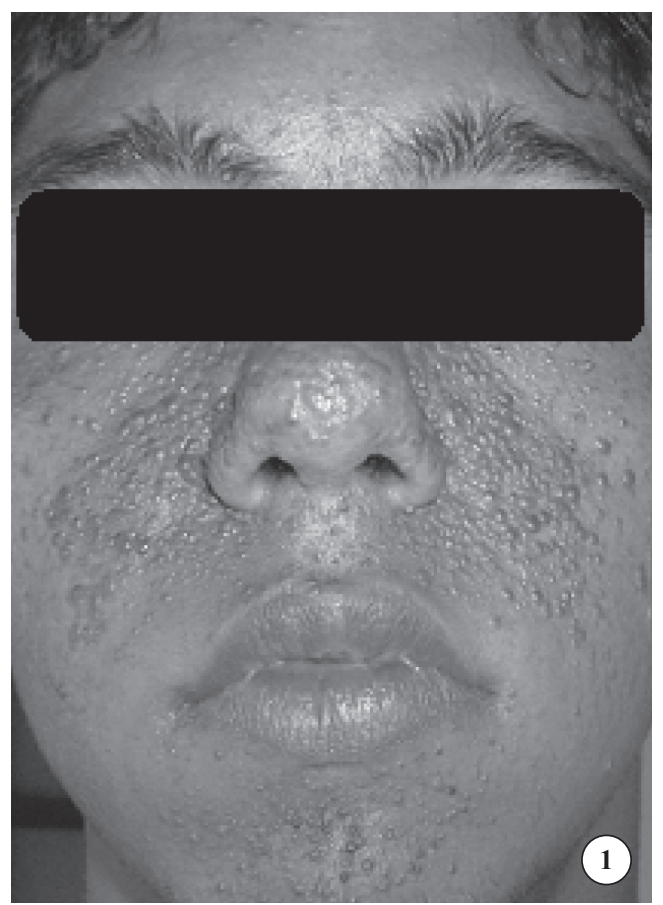

Figura 1 - Hamartomas em região nasal, malar e mentoniana Figura 2 - Hamartomas subungueais

Figura 3 - Mancha hipocrômica em região escapular à esquerda

A mãe, que o acompanhava, relatou ser o paciente portador de Esclerose Tuberosa, a qual foi diagnosticado - quando o paciente tinha 6 meses de idade, após um episódio de crise convulsiva - por uma dermatologista, que correlacionou as manchas hipocrômicas com o quadro neurológico. A mãe foi então orientada a procurar um neurologista, o qual solicitou alguns exames para gicas típicas. É, portanto, de suma importância o conhecimento dessas manifestações para o diagnóstico precoce da doença, uma vez que a patologia demanda uma rigorosa investigação do envolvimento sistêmico.

\section{Relato de Caso}

Paciente masculino, 19 anos, solteiro, estudante, natural de Além Paraíba-MG, residente em Volta Redonda-RJ, deu entrada no pronto-socorro do Hospital São João Batista em março de 2009 com crise convulsiva tônicoclônica focal, sendo medicado com Diazepam e Fenitoína, apresentando melhora do quadro. Após sua estabilização, foi observado, durante o exame físico, a presença de hamartomas em região nasal, malar, mentoniana e subungueais (Figura 1 e 2), além de manchas hipocrômicas pelo corpo (Figura 3).
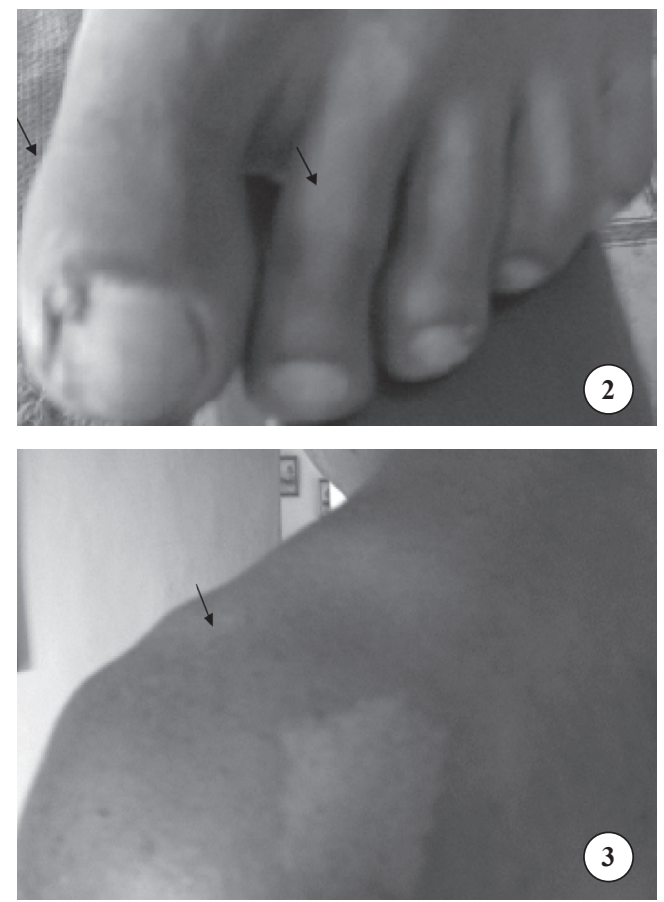

melhor investigação. Aos 3 anos de idade, foram realizados o eletroencefalograma, que evidenciou moderados sinais de disfunção de caráter inespecífico das estruturas centroencefálicas durante o sono e a Tomografia computadorizada do crânio, que demonstrou nódulos subependimais calcificados periventriculares (Figura 4) e cisto sub-aracnoideo frontal à esquerda" (Figura 5). 


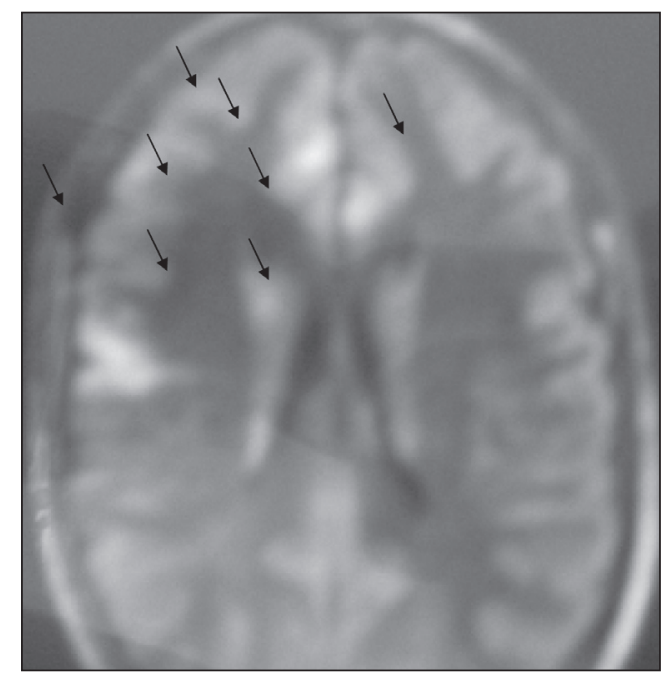

Figura 4 - Tomografia Computadorizada de crânio: nódulos subependimais calcificados periventriculares

A mãe relata que, aos 4 anos de idade surgiram os primeiros hamartomas em face e os subungueais, que se proliferaram na adolescência. Relata ainda que o paciente é o único filho do casal e desconhece caso semelhante na família. O paciente é ativo, com convívio social normal, ausência de retardo mental, em uso contínuo de carbamazepina, topiramato e fenitoína. Detalha a mãe que as crises convulsivas costumavam ocorrer quando o paciente adormecia, porém, após a inclusão da fenitoína no tratamento, as crises vêm ocorrendo ao despertar, no período da manhã.

O paciente está sendo acompanhado por um Neurologista e não há evidência clínica de acometimento de outros órgãos.

\section{Discussão}

A ET é uma doença multissistêmica de herança autossômica dominante que, em 60\% a 75\% dos pacientes, surge como consequência de mutação espontânea, sem acometer um dos pais ${ }^{3}$.

A doença é causada por mutações no gene-ET1 ou gene-ET2. O gene-ET1, também denominado complexo esclerose tuberosa 1 , está localizado no braço longo do cromossomo 9 e é responsável pela produção da proteína hamartina; o gene-ET2, também denominado complexo esclerose tuberosa 2, está localizado no braço curto do cromossomo 16 e é responsável pela produção da proteína tuberina. Essas proteínas são supressores da divisão celular e, a mutação no gene ET1 ou ET2 determina uma perda do

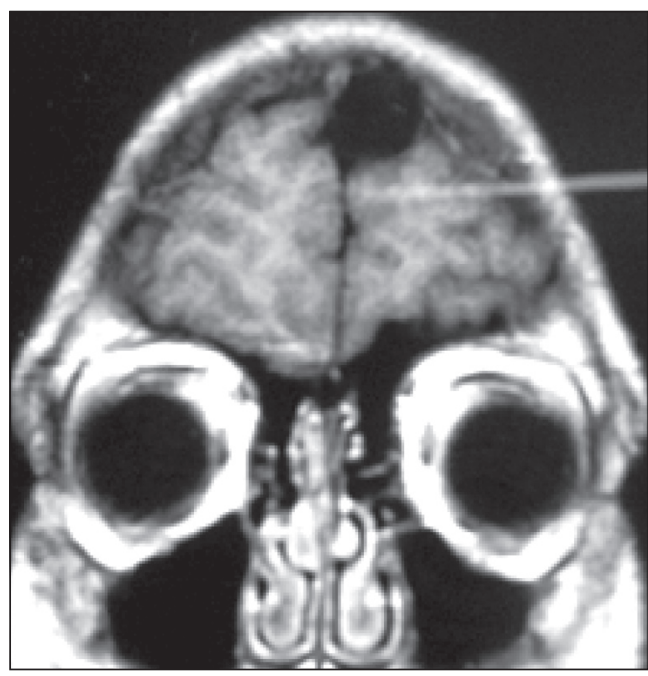

Figura 5 - Tomografia Computadorizada de crânio: cisto subaracnoideo frontal à esquerda

controle da divisão celular, o que predispõe à formação de tumores localizados em múltiplos órgãos como a pele, cérebro, coração, rins, pulmões entre outros, afetando, principalmente, os sistemas nervoso e dermatológico ${ }^{4}$. Os sinais e sintomas dependem do órgão atingido e podem ter vários níveis de gravidade. No caso apresentado, não foram detectadas manifestações em todos os sistemas comumente envolvidos. Houve predomínio de manifestações dermatológicas e achados em sistema nervoso central.

As lesões dermatológicas estão presentes, inicialmente, em $83,3 \%$ dos casos e chegam a 98,7\% com a evolução da doença, manifestando-se nas formas de manchas hipocrômicas, angiofibromas faciais, placas de Shagreen, fibromas ungueais, tumores de Köenen e placas na fronte, entre outras lesões ${ }^{1}$.

As manchas hipocrômicas (Figura 3) representam as lesões mais comuns e precoces da doença 5, o que corrobora com os achados deste estudo e são mais evidenciadas à Lâmpada de Wood. Sua presença implica maior chance de associação com epilepsia. Pelo fato dessas lesões serem relativamente comuns na população, tem pouco valor como critério diagnóstico.

Os angiofibromas ocorrem em 50 a $80 \%$ dos casos e é a mais clássica das lesões, surgindo geralmente a partir dos três anos de idade e tendem a proliferar na puberdade. São pápulas ou nódulos lisos, duros, eritemato-amarelados ou acastanhados, predominantemente localizados na porção central da face ${ }^{6}$ (Figura 1). O quadro histopatológico evidencia vasos sanguíneos dilatados e aumentados em número, permeados por fibrose dérmica. 
Os Fibromas ungueais (Figura 2), frequentes em 15 a $20 \%$ dos casos, são geralmente presentes após a puberdade ${ }^{5}$. São pápulas duras, firmes, que surgem nas dobras ungueais ou em suas adjacências.

As manifestações neurológicas mais proeminentes da ET são as crises convulsivas, retardo mental e anormalidades do comportamento. A ET é uma síndrome com moderada variabilidade de sintomas, encontrando-se diferentes níveis de comprometimento, desde crises convulsivas refratárias e retardo mental grave até inteligência normal ${ }^{7}$. No caso apresentado, a ausência de sintomatologia na família e a inteligência normal do paciente podem ser explicadas pela variabilidade de expressão da doença.

Os achados imagenológicos do cérebro mais encontrados incluem nódulos subependimais, tubérculos corticais, astrocitomas de células gigantes, áreas de hipoplasia cortical e substância cinzenta heterotópica. Os nódulos subependimais tipicamente localizados nos ventrículos laterais, com frequência, tornamse calcificados. São consideradas as lesões originalmente precursoras do termo Esclerose Tuberosa ${ }^{8}$. O paciente relatado apresenta típico envolvimento, com a presença de nódulos subependimais (Figura 4).

Não existe cura para a ET, no entanto, existe um conjunto de soluções para o tratamento dos sintomas da doença. Os doentes com epilepsia devem receber drogas antiepilépticas e em relação às lesões da pele, pode-se realizar cirurgia. Encontra-se atualmente em desenvolvimento a utilização de drogas como a Rapamicina ${ }^{9}$. A experiência inicial tem sido positiva, no entanto são necessários mais estudos para se tornar uma terapia de escolha.

O prognóstico é variável e dependente da gravidade dos sintomas. Os doentes com sintomas graves e comprometimento de vários órgãos possuem pior prognóstico.

As principais causas de morte incluem doença renal por complicações dos múltiplos angiomiolipomas e cistos renais, insuficiência renal, tumores cerebrais múltiplos ou de grandes dimensões, status epiléptico e linfangiomatose pulmonar ${ }^{10}$.

\section{Conclusão}

É de grande importância o alerta médico para a presença de manifestações típicas da ET, já que o diagnóstico precoce é determinante no que diz respeito à evolução e ao prognóstico.

Finalmente, destaca-se a importância do aconselhamento genético por tratar-se de uma doença hereditária autossômica dominante. $\mathrm{O}$ paciente é caso esporádico na família, entretanto, o risco de recorrência para sua prole é de $50 \%$.

\section{Referências Bibliográficas}

1. SARAIVA L.E.S. et al. Relevância das manifestações dermatológicas no diagnóstico precoce da esclerose tuberosa. An. Bras. Dermatol.; vol.80 suppl.2 Rio de Janeiro June/Aug., 2005.

2. NUNESMAIA H.G.S., NUNES J.C. Epidemiologia genética e clínica da esclerose tuberosa / Genetic and clinical epidemiology of tuberous sclerosis Rev. Bras. Ciênc. Saúde; 1(1/3):63-74, jan.-dez, 1997.

3. BERBERT, A.L.C.V.; FERNANDES, C.A.A. Esclerose Tuberosa. An bras Dermatol.; Rio de Janeiro. 72(1):73-77. jan./fev, 1997.

4. RENDTORFF, N.D. et al. Analysis of 65 tuberous sclerosis complex (TSC) patients by TSC2 DGGE, TSC1/TSC2 MLPA, and TSC1 long-range PCR sequencing, and report of 28 novel mutations. Human Mutation, 26 (4): 374—83, 2005.

5. ROACH E.S., DELGADO M.R. Tuberous sclerosis. Dermatologic Clin; 13(1):131.6, 1995.

6. AZULAY D.R. Esclerose tuberosa. Arq bras med; 64(6): 413-7, 1990.

7. PIRES C.F. et al. Esclerose tuberosa na infância. Dermatology Online Journal; 14 (9): 14, 2008.

8. RIDLER K. et al. Standardized whole brain mapping of tubers and subependymal nodules in tuberous sclerosis complex. Journal of Child Neurology; 19 (9): 658665, 2004. 
9. YATES, J.R. Tuberous sclerosis. Eur J Hum Genet.; 14(10): 1065-73, 2006.

10. SHEPHERD C., GOMEZ M., LIE J., CROWSON C. Causes of death in patients with tuberous sclerosis. Mayo Clin Proc; 66 (8): 792-6, 1991.

Endereço para Correspondência:

Cláudia Yamada Utagawa

claudia.utagawa@foa.org.br

Centro Universitário de Volta Redonda

Campus Três Poços

Av. Paulo Erlei Alves Abrantes, $n^{\circ} 1325$,

Três Poços - Volta Redonda / RJ

CEP: $27240-560$

Informações bibliográficas:

Conforme a NBR 6023:2002 da Associação Brasileira de Normas Técnicas (ABNT), este texto científico publicado em periódico eletrônico deve ser citado da seguinte forma: VARELLA, Paula de Oliveira; DUTRA, Leandro Dinato; SERRAZINA, Suindara Reis; BALBINO, Viviane Dias; UTAGAWA, Cláudia Yamada. A importância dos sinais dermatológicos para o diagnóstico de Esclerose Tuberosa: Relato de caso. Cadernos UniFOA. Volta Redonda, Ano V, n. 13, agosto 2010. Disponível em: <http://www.unifoa. 